\title{
Kinetics of Changes in Oxyhemoglobin Saturation During Walking and Cycling Tests in COPD
}

\author{
Ming-Lung Chuang MD, I-Feng Lin PhD, and Shih-Pin Chen MD
}

\begin{abstract}
BACKGROUND: The patterns and kinetics of changes in $\mathrm{S}_{\mathrm{pO}}$ in the 6-min walk test (6MWT) and cycling test have not been addressed in patients with COPD. METHODS: We studied 60 COPD subjects, with a mean $\pm \mathrm{SD} \mathrm{FEV}$ of $54 \pm 18 \%$ of predicted. We compared the changes in $\mathrm{S}_{\mathrm{pO}}$ $\left(\Delta \mathrm{S}_{\mathrm{pO}_{2}}\right)$ within and between the 2 tests, and the differences between the desaturators and nondesaturators. RESULTS: In the 6MWT there were 4 patterns of $\mathrm{S}_{\mathrm{pO}_{2}}$. Desaturation then resaturation was the most common $(46 \%) . \Delta \mathrm{S}_{\mathrm{pO}_{2}} \geq 3 \%$ occurred at approximately $1.2 \mathrm{~min}$, and the nadir was at $3.5 \mathrm{~min}$ where resaturation occurred thereafter. The $\Delta \mathrm{S}_{\mathrm{pO}_{2}}$ between the start and the nadir (start-vs-nadir $\left.\Delta \mathrm{S}_{\mathrm{pO}_{2}}\right)$ was greater than the start-vs-end $\Delta \mathrm{S}_{\mathrm{pO}_{2}}(P<.001)$. The desaturators had less inspiratory muscle strength, worse dyspnea, and shorter 6-min walk distance, whereas the resaturators had greater $\mathrm{FEV}_{1} / \mathrm{FVC}$ and less functional residual capacity (all $P<.05$ ). In the cycling test there were 3 patterns of $\mathrm{S}_{\mathrm{pO}_{2}}$. Desaturation was the most common (57\%). The $\Delta \mathrm{S}_{\mathrm{pO}_{2}} \geq 3 \%$ and nadir $\mathrm{S}_{\mathrm{pO}_{2}}$ occurred at $4.6 \mathrm{~min}$ and $6.6 \mathrm{~min}$, respectively, of the 6.8-min cycling exercise duration. The desaturators had lower body mass index, lower oxygen-cost diagram score, less post-exercise inspiratory muscle strength, lower diffusing capacity, lower $\mathrm{S}_{\mathrm{pO}_{2}}$, lower work during 6MWT, and lower peak exercise performance (all $P<.05$ ). In both tests, the start-vs-nadir $\Delta \mathrm{S}_{\mathrm{pO}_{2}}$ during the 6MWT was greater $(P=.02)$ but the start-vs-end $\Delta \mathrm{S}_{\mathrm{pO}_{2}}$ was similar $(P=.79)$. The desaturators in both tests had lower oxygen-cost-diagram scores $(P<.01)$ and poorer peak exercise performance. CONCLUSIONS: Measurement of start-vs-nadir $\Delta \mathrm{S}_{\mathrm{pO}_{2}}$ rather than start-vs-end $\Delta \mathrm{S}_{\mathrm{pO}_{2}}$ during the 6MWT is recommended, because start-vs-nadir $\Delta \mathrm{S}_{\mathrm{pO}_{2}}$ is greater, and the nadir $\mathrm{S}_{\mathrm{pO}_{2}}$ is earlier. In both the 6MWT and the cycling exercise test, desaturation can be predicted with the oxygen-costdiagram score, which has more capability to predict peak exercise performance than the 6MWT. Key words: 6-min walk test; incremental cardiopulmonary exercise test; desaturation; hypoxemia; COPD. [Respir Care 2014;59(3):353-362. (C) 2014 Daedalus Enterprises]
\end{abstract}

\section{Introduction}

Walking may induce hypoxemia or oxyhemoglobin desaturation (saturation of hemoglobin via pulse oximeter;

\footnotetext{
Dr Chuang is affiliated with the Division of Pulmonary Medicine, Department of Critical Care Medicine, Chung Shan Medical University Hosptial, and School of Medicine, Chung Shan Medical University, Taichung, Taiwan. Dr Chen is affiliated with the Department of Internal Medicine, Chung Shan Medical University Hospital, and the Institute of Medicine, Chung Shan Medical University, Taichung, Taiwan. Dr Lin is affiliated with the Institute of Public Health, National Yang Ming University, Taipei, Taiwan.
}

This study was partly supported by grant CSH-2012-C-023 from the Chung Shan Medical University Research Program and grant 443 from decrease in $\mathrm{S}_{\mathrm{pO}_{2}}$ ) more profoundly than does cycling in patients with COPD. ${ }^{1-5}$ The differences in the change $(\Delta)$ in $\mathrm{P}_{\mathrm{aO}_{2}}$ or $\mathrm{S}_{\mathrm{pO}_{2}}$ between walking and cycling are due to utilizing different muscle groups for ventilatory compensation for exercise demand. ${ }^{1,3,6,7}$ However, the results of previous reports have been inconsistent, ${ }^{8,9}$ perhaps due to

\footnotetext{
the Chang Gung Medical Research Program. The authors have disclosed no conflicts of interest.

Correspondence: Ming-Lung Chuang MD, Division of Pulmonary Medicine, Department of Critical Care Medicine, Chung Shan Medical University Hospital, \#110, Section 1, Chien-Kuo North Road, South District, Taichung 40201, Taiwan. E-mail: yuan1007@ms36.hinet.net.
}

DOI: $10.4187 /$ respcare.02494 


\section{Kinetics of Changes in Oxyhemoglobin Saturation During Walking and Cycling}

differences in the definitions of desaturation, modes of exercise, and patient populations. ${ }^{10}$

The patterns and kinetics of $\mathrm{S}_{\mathrm{pO}_{2}}$ during different exercise modes may also influence the magnitude of $\Delta \mathrm{S}_{\mathrm{pO}_{2}}$. There are 3 types of $\mathrm{S}_{\mathrm{pO}_{2}}$ change during the 6-min walk test (6MWT): desaturation increases throughout the test, no desaturation, ${ }^{4}$ and desaturation then resaturation during the last few minutes. ${ }^{4,9,11}$ But these $\mathrm{S}_{\mathrm{pO}_{2}}$ patterns have rarely been reported. $\Delta \mathrm{S}_{\mathrm{pO}_{2}}$ during the $6 \mathrm{MWT}$ may be influenced by the patient's COPD stage ${ }^{4,12,13}$ and by the test protocol, which is self-pacing, ${ }^{14}$ conducted with "neutral" verbal encouragement, and with rest allowed. ${ }^{5,11} \Delta \mathrm{S}_{\mathrm{pO}_{2}}$ during the incremental cycling test may also be influenced by COPD stage ${ }^{15,16}$ but only rarely by differences in the test protocol, which is computer-controlled, conducted with verbal encouragement, and continuous to symptom-limited exhaustion.

We hypothesized that $3 \Delta \mathrm{S}_{\mathrm{pO}_{2}}$ patterns may occur in one individual test, and that the nadir $\mathrm{S}_{\mathrm{pO}_{2}}$ may occur midway during the 6MWT, so merely subtracting the end $\mathrm{P}_{\mathrm{aO}_{2}}{ }^{7}$ or $\mathrm{S}_{\mathrm{pO}_{2}}{ }^{17}$ from the start $\mathrm{P}_{\mathrm{aO}_{2}}$ or $\mathrm{S}_{\mathrm{pO}_{2}}$ may be inappropriate. ${ }^{11}$ We investigated how the patterns and kinetics of $\Delta \mathrm{S}_{\mathrm{pO}_{2}}$ differ in the 6MWT and the cycling exercise test, and the differences between subjects with and without desaturation.

\section{Methods}

The Institutional Review Boards of Chang Gung Memorial Hospital and Chung Shan Medical University Hospital approved this study (study numbers CMRP443 and CS11144), and all of the subjects provided written informed consent. A cohort of COPD subjects underwent the 6MWT and symptom-limited cycling test in random order.

\section{Subjects}

The diagnosis of COPD was based on the Global Initiative for Chronic Obstructive Lung Disease criteria. ${ }^{18}$ All the subjects were clinically stable for 1 month before undergoing the 2 exercise tests, which were conducted within 2 weeks of each other. We excluded patients who had important comorbidities, needed home oxygen, or participated in any physical training program during this study.

\section{Protocols and Measurements}

Oxygen-Cost Diagram. The oxygen-cost diagram was used as a scale for daily activities, assessed by the subjects themselves. The subjects were asked to indicate a point on an oxygen-cost diagram, a 100-mm long vertical line with everyday activities listed alongside the line, spaced according to the oxygen requirement associated with the performance of each task, above which their breathless-

\section{QUICK LOOK}

\section{Current knowledge}

The 6-min walk test is the standard for determining exercise intolerance in patients with chronic lung disease. The kinetics of oxygen desaturation during the 6-min walk test versus during cycle ergometry has not been directly compared in patients with COPD.

\section{What this paper contributes to our knowledge}

Monitoring $\mathrm{S}_{\mathrm{pO}_{2}}$ and recording the $\Delta \mathrm{S}_{\mathrm{pO}_{2}}$ between the starting $\mathrm{S}_{\mathrm{pO}_{2}}$ and the nadir $\mathrm{S}_{\mathrm{pO}_{2}}$ was superior to determining the $\Delta \mathrm{S}_{\mathrm{pO}_{2}}$ between the beginning and end of the test. Exertional desaturation in both tests predicted poorer peak exercise performance than did walking performance.

ness limited them. ${ }^{19}$ The distance from zero was measured and scored.

Pulmonary Function Testing. Pulmonary function tests were performed before the exercise tests. The FVC, FEV ${ }_{1}$, forced expiratory flow during the middle half of the FVC maneuver, TLC, and RV were measured by pressure-sensitive body plethysmography (6200 Autobox DL, SensorMedics, Yorba Linda, California). The best of 3 technically satisfactory readings was used. ${ }^{20,21}$ All lung function data were obtained after inhaling $400 \mu \mathrm{g}$ of fenoterol $\mathrm{HCl}$. The diffusing capacity of the lung for carbon monoxide $\left(\mathrm{D}_{\mathrm{LCO}}\right)$ was measured with the single-breath technique. Simple volume calibration was done using a 3 -L syringe before each test.

The maximum inspiratory pressure, indicating inspiratory muscle strength, was measured (MicroRPM, Micro Medical/CareFusion, San Diego, California), starting at residual volume, with a nose clip in place, with forceful inspiratory maneuver with sustained maximal effort for 1-3 s. Maximum expiratory pressure, for expiratory muscle strength, was measured starting at TLC. Both maximum inspiratory pressure and maximum expiratory pressure were performed, before and after the cycling test, with a 1-min recovery period in between. The best result was recorded for analysis.

6-Min Walk Test. The 6MWTs were conducted in a temperature-controlled, 20-m corridor. Blood pressure and breathing frequency were measured. Dyspnea was measured with the modified Borg scale, ${ }^{22}$ at rest, midway, and at the end of the walk. The 6MWT was conducted with the help of verbal encouragement, per the American Thoracic Society recommendations. ${ }^{14} \mathrm{~S}_{\mathrm{pO}_{2}}$ and pulse rate (3760, Datex-Ohmeda/GE Healthcare, Madison, Wisconsin, or 


\section{Kinetics of Changes in Oxyhemoglobin Saturation During Walking and Cycling}

N-595, Nellcor/Covidien, Boulder, Colorado) were continuously measured, to maximize the signal and minimize motion artifacts. The signals were stable before the recording, and were stored as 4-s averages. However, the data in this report are for each minute only.

The pulse oximeters were validated with arterial blood gas analysis. ${ }^{12}$ The $\Delta \mathrm{S}_{\mathrm{pO}_{2}}$ patterns were identified and classified independently by 2 investigators. Consensus was reached after discussion if there were any discrepancies. The $\Delta \mathrm{S}_{\mathrm{pO}_{2}}$ values are reported as start-vs-nadir $\Delta \mathrm{S}_{\mathrm{pO}_{2}}$ and start-vs-end $\Delta \mathrm{S}_{\mathrm{pO}_{2}}$. The minimum clinically important $\mathrm{S}_{\mathrm{pO}_{2}}$ difference was defined as a $\geq 3 \%$ decrease after the start of exercise. ${ }^{12}$

Each subject performed the 6MWT twice, with a $>30 \mathrm{~min}$ rest in between. The longest distance walked was recorded, and the work of walking was calculated as distance in kilometers times body weight in kilograms. ${ }^{9}$

Maximum Cardiopulmonary Exercise Test. After a 2-min rest from the mounting the computer-controlled, electronically braked cycle ergometer (Lode, Corival, Groningen, Netherlands), each subject began a 2-min period of unloaded cycling, followed by a ramp-pattern exercise test to the limit of tolerance. The work rate was set to increase at 5-20 watts per min, according to pre-determined fitness, based on a derived protocol formula. ${ }^{23}$

Heart rate, $\mathrm{S}_{\mathrm{pO}_{2}}$, oxygen uptake, carbon dioxide output, minute volume, blood pressure, and Borg dyspnea score were measured. Pulse rate and $\mathrm{S}_{\mathrm{pO}_{2}}$ (3740, Datex-Ohmeda/GE Healthcare, Madison, Wisconsin, or 7500, Nonin, Plymouth, Minnesota) were measured continuously. The pneumotachograph was calibrated with a 3-L syringe before each test. The $\mathrm{O}_{2}$ and $\mathrm{CO}_{2}$ analyzers were calibrated with standard gases.

\section{Statistical Analysis}

Data are reported as mean \pm SD. Unpaired and paired $t$ tests were used to compare the means between the 2 independent groups and 2 dependent groups, respectively. The chi-square or Fisher exact test was used to compare the proportion of the categorical variables between the 2 groups. One-way analysis of variance was used to compare the 3 groups of consistent changes in the variables. All tests were 2-sided, and statistical significance was set at $P<.05$. All statistical analyses were performed with statistics software (SAS 9, SAS Institute, Cary, North Carolina, and Origin 4.0, MicroCal/GE Healthcare, Little Chalfont, Buckinghamshire, United Kingdom).

Sample Size and Power Calculations. The changes in $\mathrm{S}_{\mathrm{pO}_{2}}$ between start and nadir (start-vs-nadir $\Delta \mathrm{S}_{\mathrm{pO}_{2}}$ ) during the 6MWT were the primary outcomes. Using statistics software (NCSS 9, NCSS, Kaysville, Utah) we estimated
Table 1. Demographic and Lung Function Data From 60 Subjects With COPD

\begin{tabular}{|c|c|}
\hline Age, mean $\pm \mathrm{SD}$ y & $66.7 \pm 6.9$ \\
\hline Male/female, no. & $59 / 1$ \\
\hline Height, mean $\pm \mathrm{SD} \mathrm{cm}$ & $164.3 \pm 6.4$ \\
\hline Weight, mean $\pm \mathrm{SD} \mathrm{kg}$ & $60.9 \pm 12.2$ \\
\hline Body mass index, mean $\pm \mathrm{SD} \mathrm{kg} / \mathrm{m}^{2}$ & $22.4 \pm 3.7$ \\
\hline Smoking history, mean \pm SD pack-years & $39.4 \pm 14.9$ \\
\hline Hypertension, no. & 22 \\
\hline Diabetes mellitus, no. & 4 \\
\hline Heart disease, no. & 1 \\
\hline Oxygen-cost diagram, mean \pm SD mm & $70 \pm 15$ \\
\hline $\mathrm{FVC}$, mean $\pm \mathrm{SD} \mathrm{L}$ & $2.7 \pm 0.7$ \\
\hline $\mathrm{FVC}$, mean $\pm \mathrm{SD} \%$ predicted & $89 \pm 23$ \\
\hline $\mathrm{FEV}_{1}$, mean $\pm \mathrm{SD} \mathrm{L}$ & $1.3 \pm 0.5$ \\
\hline $\mathrm{FEV}_{1}$, mean $\pm \mathrm{SD} \%$ predicted & $54 \pm 18$ \\
\hline $\mathrm{FEF}_{25-75 \%}$, mean $\pm \mathrm{SD} \mathrm{L} / \mathrm{s}$ & $0.51 \pm 0.36$ \\
\hline $\mathrm{FEF}_{25-75 \%}$, mean $\pm \mathrm{SD} \%$ predicted & $18 \pm 13$ \\
\hline \multicolumn{2}{|l|}{ COPD stage, no. } \\
\hline I & 4 \\
\hline II & 30 \\
\hline III & 21 \\
\hline IV & 5 \\
\hline $\mathrm{FEV}_{1} / \mathrm{FVC}$, mean $\pm \mathrm{SD}$ & $0.48 \pm 0.13$ \\
\hline TLC, mean \pm SD L & $5.8 \pm 1.3$ \\
\hline TLC, mean \pm SD $\%$ predicted & $117 \pm 27$ \\
\hline $\mathrm{RV} / \mathrm{TLC}$, mean $\pm \mathrm{SD}$ & $0.51 \pm 0.11$ \\
\hline $\mathrm{D}_{\mathrm{LCO}}$, mean $\pm \mathrm{SD} \mathrm{mL} / \mathrm{mm} \mathrm{Hg} / \mathrm{min}$ & $15.6 \pm 5.8$ \\
\hline $\mathrm{D}_{\mathrm{LCO}}$, mean $\pm \mathrm{SD} \%$ predicted & $77 \pm 26$ \\
\hline $\begin{array}{l}\mathrm{FEF}_{25-75 \%} \text { forced expirtory flow during middle half of } \mathrm{FVC} \\
\mathrm{RV}=\text { residual volume }\end{array}$ & \\
\hline
\end{tabular}

that a sample size of 21 subjects in each group would be required to detect a $\Delta \mathrm{S}_{\mathrm{pO}_{2}}$ of $3 \%$ with a standard deviation of the change of $4 \%,{ }^{9}$ statistical power of 0.90 , and alpha of .05 .

\section{Results}

We enrolled 60 subjects (Table 1), 37 at Chang Gung Memorial Hospital and 23 at Chung Shan Medical University Hospital. Most had stage II or stage III COPD, with elevated static air trapping and mildly impaired diffusing capacity.

\section{6-Min Walk Test}

All the subjects completed the 6MWT, but 3 were excluded due to unstable baseline recordings. Overall, the start-vs-end $\Delta \mathrm{S}_{\mathrm{pO}_{2}}$ was $3.7 \pm 5.1 \%(P<.001)$ (Table 2, Fig. 1) and $70 \%$ of subjects had desaturation $\left(\Delta \mathrm{S}_{\mathrm{pO}_{2}} \geq 3 \%\right)$ at $1.2 \mathrm{~min}$ (see Fig. $1 \mathrm{~B}, P<.001$ ). The desaturation group 
Table 2. $\mathrm{S}_{\mathrm{pO}_{2}}$ and Exercise Duration

\begin{tabular}{|c|c|c|c|}
\hline & $\begin{array}{c}6 \mathrm{MWT}^{*} \\
\text { mean } \pm \mathrm{SD} \\
(n=57)\end{array}$ & $\begin{array}{c}\text { Cycling Test } \dagger \\
\text { mean } \pm \text { SD } \\
(n=45)\end{array}$ & $P$ \\
\hline \multicolumn{4}{|l|}{$\mathrm{S}_{\mathrm{pO}_{2}}, \%$} \\
\hline Start & $95.2 \pm 2$ & $96.5 \pm 1.8$ & $<.001$ \\
\hline Nadir & $87.2 \pm 6.7 \ddagger$ & $91.3 \pm 3 \ddagger$ & .003 \\
\hline End & $91.4 \pm 5.6 \neq$ & $92.4 \pm 3.4 \ddagger$ & .18 \\
\hline$\Delta \mathrm{S}_{\mathrm{pO}_{2}}$ start vs nadir, $\%$ & $7.8 \pm 5.6 \S$ & $4.9 \pm 3.1$ & .02 \\
\hline$\Delta \mathrm{S}_{\mathrm{pO}_{2}}$ start vs end, $\%$ & $3.7 \pm 5.1$ & $3.8 \pm 3.4$ & .79 \\
\hline $\begin{array}{l}\text { Time from start to nadir } \mathrm{S}_{\mathrm{pO}_{2}} \text {, } \\
\text { min }\end{array}$ & $3.5 \pm 1.4$ & $6.6 \pm 2.5$ & $<.001$ \\
\hline Exercise duration, min & 6 & $6.8 \pm 2.4$ & .02 \\
\hline \multicolumn{4}{|c|}{ 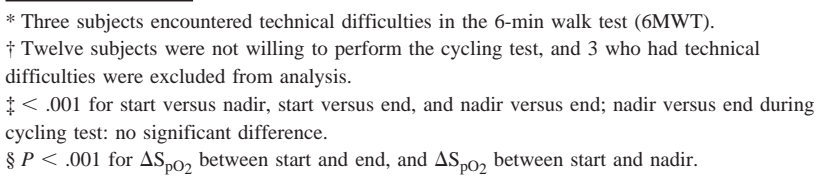 } \\
\hline
\end{tabular}
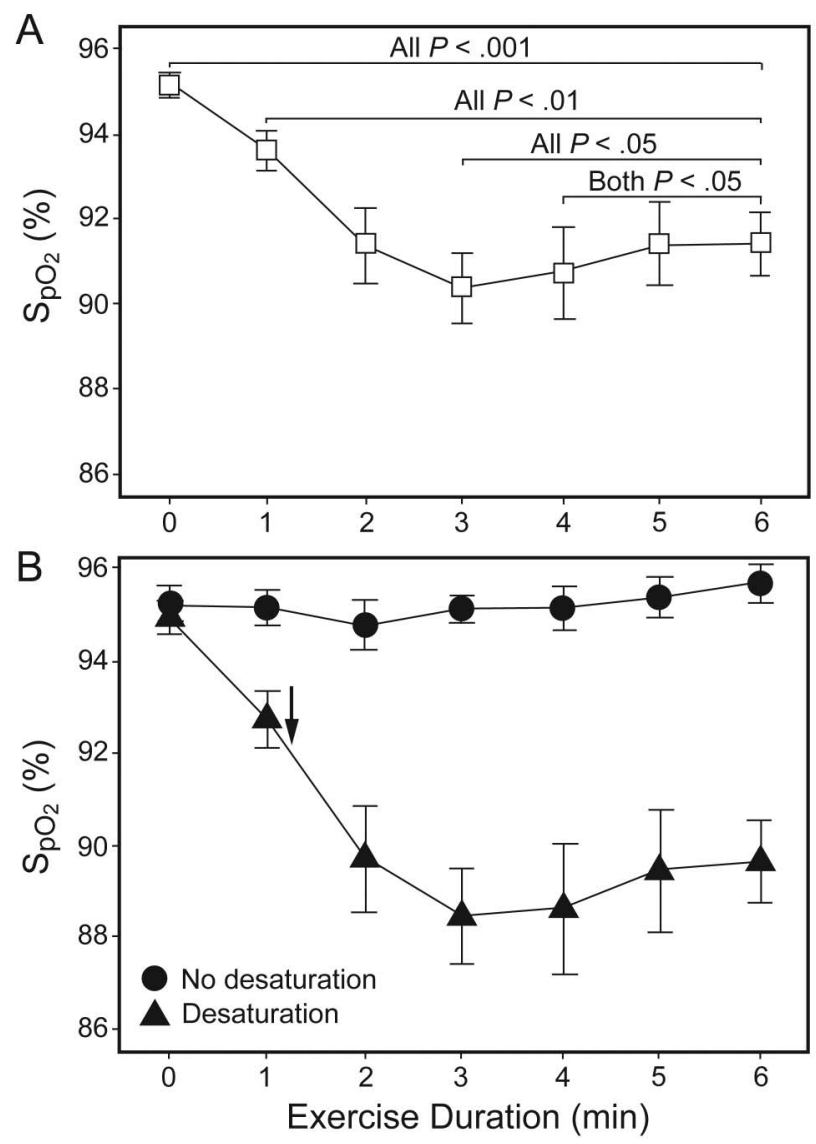

Fig. 1. A: Mean $\pm \mathrm{SD} \mathrm{S}_{\mathrm{pO}_{2}}$ in all 57 subjects during the 6-min walk test. B: Mean $\pm \mathrm{SD} \mathrm{S}_{\mathrm{pO}_{2}}$ in subjects with $(n=40)$ and without $(n=17)$ desaturation. The arrow indicates the point at which $\mathrm{S}_{\mathrm{pO}_{2}}$ had decreased by $3 \%$, which we considered the minimum clinically important desaturation.
( $n=40$ of the total 57) was further separated into 3 subgroups: $3(5 \%)$ of 57 subjects desaturated after the third minute; $26(46 \%)$ subjects desaturated $(7.8 \pm 5.6 \%$, $P<.001)$ during the first $3 \mathrm{~min}$ and then began to resaturate at $3.5 \pm 1.4 \mathrm{~min}$ (see Table 2 and Fig. 2); and 11 (19\%) subjects began desaturating immediately and did not resaturate during the 6MWT. The mean start-vs-end $\Delta \mathrm{S}_{\mathrm{pO}_{2}}$ was less than the start-vs-nadir $\Delta \mathrm{S}_{\mathrm{pO}_{2}}(P<.001)$.

The 40 subjects $(70 \%)$ with desaturation during the 6MWT had significantly less inspiratory muscle strength $(P=.01)$, worse dyspnea $(P=.03)$, and shorter walk distance $(P=.05)$ than the subjects without desaturation (Table 3). Subjects with desaturation then resaturation had greater $\mathrm{FEV}_{1} / \mathrm{FVC}(P=.01)$ and less air trapping $(P=.047)$ than those with desaturation.

\section{Cycling Test}

Fifty of the 60 subjects completed the symptom-limited cycling test. Thirteen were excluded (10 did not want to perform the test, and 3 had technical difficulties) so $\mathrm{S}_{\mathrm{pO}_{2}}$ analysis was performed on the data from 47 subjects (see Table 2).

There were 2 typical $\mathrm{S}_{\mathrm{pO}_{2}}$ patterns during the cycling test (Fig. 3). Two subjects had irregular $\Delta \mathrm{S}_{\mathrm{pO}}$ patterns, which are not shown in Figure 3. In total, 27 (57\%) of the 47 subjects desaturated during the cycling test. Desaturation was initially detected at approximately $30 \%$ of the loaded exercise (ie, at approximately $2 \mathrm{~min}$ in the 6.8 -min exercise duration). $\Delta \mathrm{S}_{\mathrm{pO}_{2}} \geq 3 \%$ was detected at $68 \%$ of the loaded exercise (ie, at approximately $4.6 \mathrm{~min}$ of the total exercise duration), and the nadir $\mathrm{S}_{\mathrm{pO}_{2}}$ at $97 \%$ (ie, $6.6 \mathrm{~min}$ of the total exercise duration) (see Table 2 and Fig. 3). The subjects who desaturated had lower body mass index and oxygen-cost-diagram score, poorer lung function, more tachypnea and dyspnea, and lower work of walking during the 6MWT. They also had poorer cardiopulmonary function during the peak exercise test (Table 4).

\section{Comparison of 2 Exercise Tests}

The $\mathrm{S}_{\mathrm{pO}_{2}}$ was significantly different between the 2 exercise tests at the start of the loaded exercise $(P<.001)$ (see Table 2). The difference in start-vs-nadir $\Delta \mathrm{S}_{\mathrm{pO}_{2}}$ was significant $(P=.02)$, but not the difference in start-vs-end $\Delta \mathrm{S}_{\mathrm{pO}_{2}}(P=.79)$. The time to $\Delta \mathrm{S}_{\mathrm{pO}_{2}} \geq 3 \%$ and nadir $\mathrm{S}_{\mathrm{pO}_{2}}$ was much earlier in the 6MWT than in the cycling test (1.2 $\mathrm{min}$ and $3.5 \mathrm{~min}$ vs $4.6 \mathrm{~min}$ and $6.6 \mathrm{~min}$, respectively) (both $P<.001$ ).

More subjects had $\Delta \mathrm{S}_{\mathrm{pO}_{2}} \geq 3 \%$ during the $6 \mathrm{MWT}$ than during the cycling test (40 vs 27 ) but that difference was not significant $(P=.28)$. Moreover, 64\% $(n=30)$ had consistent $\Delta \mathrm{S}_{\mathrm{pO}_{2}}$ in the 2 tests (Table 5). Those with desaturation in both tests had poorer oxygen-cost-diagram 

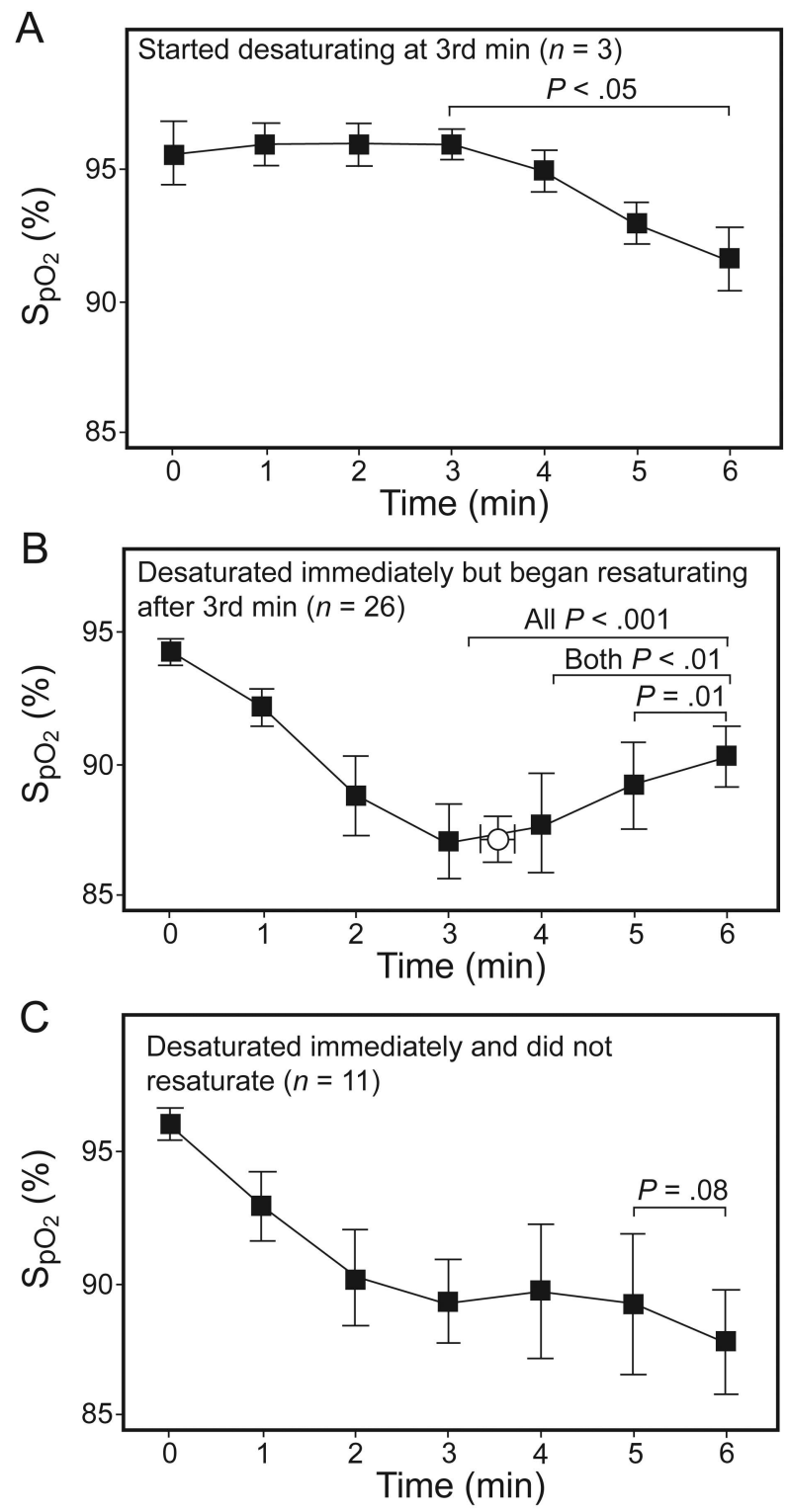

Fig. 2. $\mathrm{S}_{\mathrm{pO}_{2}}$ during the 6-min walk test in the 40 subjects who desaturated. A: Three subjects who started desaturating after the third minute and did not resaturate (all $P<.05$ for the comparison of the mean $\mathrm{S}_{\mathrm{pO}_{2}}$ with the third minute). B: Twenty-six subjects who began desaturating immediately but then resaturated (the open circle indicates the $\mathrm{S}_{\mathrm{pO}_{2}}$ nadir at $3.5 \pm 1.4 \mathrm{~min}, P<.001$ for the comparison of the $\mathrm{S}_{\mathrm{pO}_{2}}$ of the fifth and sixth minutes with the third minute; $P<.001$ for the comparisons of the fifth and sixth minute with the fourth minute; $P<.01$ for the comparison of the sixth minute with the fifth minute). C: Eleven subjects who began desaturating immediately and continued desaturating throughout the test $(P=.08$ for the comparison of the sixth minute with the fifth minute).

score $(P<.01)$ and cardiopulmonary function at peak exercise ( $P=.04$ to .006) (see Table 5). Thus, the oxygencost-diagram score might predict exertional desaturation in both submaximal and maximum exercise testing.

\section{Discussion}

The present study has several important findings. First, in the 6MWT, the start-vs-nadir $\Delta \mathrm{S}_{\mathrm{pO}_{2}}$ was much greater than the start-vs-end $\Delta \mathrm{S}_{\mathrm{pO}_{2}}$ (see Fig. 1 and Table 2), and the start-vs-nadir $\Delta \mathrm{S}_{\mathrm{pO}_{2}}$ during the 6MWT was greater than that during the cycling test (see Figs. 1 and 3 and Table 2). Second, the time to $\Delta \mathrm{S}_{\mathrm{pO}_{2}} \geq 3 \%$ and to nadir $\mathrm{S}_{\mathrm{pO}_{2}}$ occurred much earlier in the 6MWT than in the cycling test (1.2 and $3.5 \mathrm{~min}$ vs 4.6 and $6.6 \mathrm{~min}$, respectively, both $P<.001)$. Therefore, during the 6MWT the startvs-nadir $\Delta \mathrm{S}_{\mathrm{pO}_{2}}$ is more important than the start-vs-end $\Delta \mathrm{S}_{\mathrm{pO}_{2}}$.

\section{6-Min Walk Test}

The $\mathrm{S}_{\mathrm{pO}_{2}}$ measurement for patients with COPD during the $6 \mathrm{MWT}$ has been recommended for routine use because of the high incidence of desaturation ${ }^{5,24}$ and the related severity ${ }^{25}$ and mortality. ${ }^{26}$ In the American Thoracic Society guidelines it is an optional measurement. ${ }^{14}$

In our study we observed $4 \mathrm{~S}_{\mathrm{pO}_{2}}$ patterns (see Figs. 1 and 2). The 26 (46\%) subjects who resaturated during the second half of the $6 \mathrm{MWT}$ had better $\mathrm{FEV}_{1} / \mathrm{FVC}$ and smaller FRC than the subjects who did not resaturate (both $P<.05$, see Table 3). These subjects may have slowed down of their own volition, or even rested, to compensate for ventilation when $\mathrm{S}_{\mathrm{pO}_{2}}$ reached the nadir. This is supported by a recent study. ${ }^{11}$ Nonetheless, walking-induced desaturation remained steady despite taking a rest. ${ }^{5}$

This issue of measuring start-vs-nadir $\Delta \mathrm{S}_{\mathrm{pO}_{2}}$ during the $6 \mathrm{MWT}$ was first raised, recently, by Fiore et al. ${ }^{11} \mathrm{How}-$ ever, in the present study the start-vs-nadir $\Delta \mathrm{S}_{\mathrm{pO}_{2}}$ was greater and the start-vs-end $\Delta \mathrm{S}_{\mathrm{pO}_{2}}$ was smaller than in Fiore's study ( $7.8 \%$ vs $7 \%$ and $3.7 \%$ vs $6 \%$, respectively). And the proportion of subjects who resaturated was greater in the present study than in Fiore's study (26/40 vs 5/22, $P=.001)$. Also, Fiore did not present the kinetics of $\mathrm{S}_{\mathrm{pO}_{2}}$ changes during the 6MWT.

The time to desaturation in the 6MWT predicts 24-hour $\mathrm{S}_{\mathrm{pO}_{2}}$ changes in COPD patients with $\mathrm{P}_{\mathrm{aO}_{2}}$ between 60 and $70 \mathrm{~mm} \mathrm{Hg} .{ }^{27}$ Exertional desaturation after the first minute of the $6 \mathrm{MWT}$ forecasts a $74 \%$ probability of desaturation in daily activities, whereas exertional desaturation after 3.5 min of the 6MWT negatively predicts (100\%) desaturation in whole-day events. ${ }^{27}$ Most previous studies have reported start-vs-end $\Delta \mathrm{S}_{\mathrm{pO}_{2}}{ }^{4,8,17,28}$ or start-vs-end $\Delta \mathrm{P}_{\mathrm{aO}_{2}}{ }^{7}$ but no differences in start-vs-end $\Delta \mathrm{S}_{\mathrm{pO}_{2}}$ or start-vs-end $\Delta \mathrm{P}_{\mathrm{aO}_{2}}$ between the 2 modes of exercise have been reported in previous studies ${ }^{7,8}$ or in the present one. One study reported $\mathrm{S}_{\mathrm{pO}_{2}}$ at the third minute, but the nadir $\mathrm{S}_{\mathrm{pO}_{2}}$ might not occur during the third minute, thereby missing the point. ${ }^{4}$ 


\section{Kinetics of Changes in Oxyhemoglobin Saturation During Walking and Cycling}

Table 3. Physiologic Data From Subjects Who Conducted the 6-Minute Walk Test

\begin{tabular}{|c|c|c|c|c|}
\hline & $\begin{array}{c}\text { No } \\
\text { Desaturation } \\
\text { Group } \\
(n=17)\end{array}$ & $\begin{array}{c}\text { Desaturation } \\
\text { Group } \\
(n=40)\end{array}$ & & $P$ \\
\hline Oxygen-cost diagram score, mm & $75 \pm 14$ & $67 \pm 15$ & & .07 \\
\hline $\begin{array}{l}\text { Diffusing capacity of the lung for carbon monoxide, } \\
\% \text { predicted }\end{array}$ & $87 \pm 24$ & $73 \pm 27$ & & .07 \\
\hline Maximum inspiratory pressure, $\mathrm{cm}_{2} \mathrm{O}$ & $80 \pm 9$ & $66 \pm 19$ & & .01 \\
\hline \multicolumn{5}{|l|}{ 6-min walk test results } \\
\hline Borg dyspnea score, end & $2 \pm 1.4$ & $3.2 \pm 2.4$ & & .03 \\
\hline \multicolumn{5}{|l|}{ Heart rate } \\
\hline 4th min & $109 \pm 17$ & $124 \pm 34$ & & .06 \\
\hline 5th min & $110 \pm 17$ & $124 \pm 30$ & & .06 \\
\hline Distance, $\mathrm{m}$ & $442 \pm 79$ & $387 \pm 118$ & & .05 \\
\hline Sub-groups & & $\begin{array}{c}\text { Desaturation- } \\
\text { Resaturation } \\
\text { Group } \\
(n=26)\end{array}$ & $\begin{array}{c}\text { Desaturation } \\
\text { Group } \\
(n=14)^{*}\end{array}$ & \\
\hline $\mathrm{FEV}_{1} / \mathrm{FVC}$ & & $0.52 \pm 0.25$ & $0.4 \pm .13$ & .01 \\
\hline Total lung capacity, L & & $5.5 \pm 4.2$ & $6.1 \pm 1.1$ & .07 \\
\hline Functional residual capacity, L & & $3.8 \pm 4.8$ & $4.5 \pm 1.2$ & .047 \\
\hline
\end{tabular}

These 14 subjects included 11 subjects who began desaturating at the start of walking and continued desaturing throughout the test, plus 3 subjects with desaturation from the 3rd minute until the end.

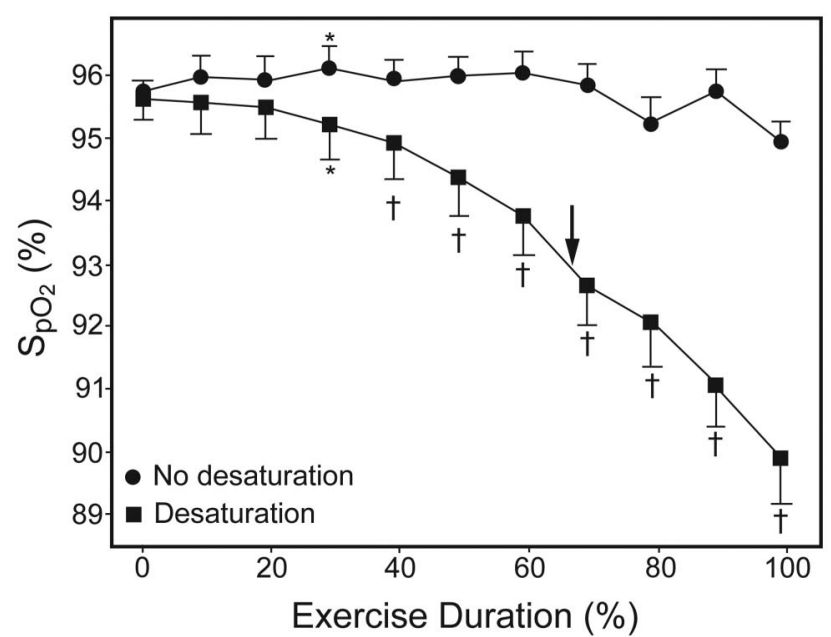

Fig. 3. $\mathrm{S}_{\mathrm{pO}_{2}}$ during the cycling test in 45 subjects: 18 who did not desaturate $\geq 3 \%$, and 27 who desaturated $\geq 3 \%$. ${ }^{*} P<.05$ and $\dagger P<.001$ for comparison with $\mathrm{S}_{\mathrm{pO}_{2}}$ at the start of the cycling test. The arrow indicates the point at which $\mathrm{S}_{\mathrm{pO}_{2}}$ had decreased by $3 \%$, which we considered the minimum clinically important desaturation.

The subjects who desaturated had a non-significant lower mean oxygen-cost-diagram score and diffusing capacity, significantly less inspiratory muscle strength, more dyspnea, shorter walk distance, and relative tachycardia during the walk test (all $P<.05$, Table 3 ). One previous study reported that the mean $\mathrm{S}_{\mathrm{pO}_{2}}$ during the 6MWT was modestly related to lung function $\left(\mathrm{D}_{\mathrm{LCO}}, \mathrm{FEV}_{1} / \mathrm{FVC}\right.$, and peak flow, $r=0.48-0.55$ ) but not related to dyspnea or walk distance. ${ }^{29}$ Another study reported that resting $\mathrm{S}_{\mathrm{pO}_{2}}$ was significantly related to $\mathrm{FEV}_{1}$ and walk distance, ${ }^{5}$ and to $\mathrm{FEV}_{1}$ plus forced expiratory flow during the middle half of the FVC maneuver. ${ }^{30}$ The sensitivity and specificity of exertional desaturation were $75 \%$ when the $\mathrm{D}_{\mathrm{LCO}}$ threshold was set at $60 \%$ of predicted. ${ }^{31} \mathrm{D}_{\mathrm{LCO}}>80 \%$ of predicted plus resting $\mathrm{S}_{\mathrm{pO}_{2}}$ has been used to exclude the evolution of exertional desaturation. ${ }^{32}$ The disagreement in the variables of lung function, dyspnea score, and walk distance in relation to $\mathrm{S}_{\mathrm{pO}_{2}}$ between the present study and previous reports might be due to the different definitions of $\mathrm{S}_{\mathrm{pO}_{2}}$ and different COPD populations. ${ }^{10}$

\section{Cycling Test}

Non-desaturation may be due to increased ventilation and improved ventilation/perfusion matching. The mechanisms of $\mathrm{S}_{\mathrm{pO}_{2}}$ desaturation are related to hypoventilation secondary to airway obstruction, $, 412,33$ decreased mixed venous $\mathrm{P}_{\mathrm{O}_{2}}$, deterioration of ventilation/perfusion matching and diffusing capacity, and increased shunting, ${ }^{10,33}$ but not necessarily to increased pulmonary vascular resistance. ${ }^{34}$

In the present study, body mass index, oxygen-costdiagram score, lung function (including peak flow and 


\section{Kinetics of Changes in Oxyhemoglobin Saturation During Walking and Cycling}

Table 4. Physiologic Data and Test Results From Desaturators Versus Non-desaturators in the Cycling Test

\begin{tabular}{|c|c|c|c|}
\hline & $\begin{array}{c}\text { No } \\
\text { Desaturation } \\
\text { Group } \\
(n=18)\end{array}$ & $\begin{array}{c}\text { Desaturation } \\
\text { Group } \\
(n=27)\end{array}$ & $P$ \\
\hline Body mass index, $\mathrm{kg} / \mathrm{m}^{2}$ & $23.8 \pm 3.7$ & $21.7 \pm 3.3$ & .05 \\
\hline Oxygen-cost diagram score, $\mathrm{mm}$ & $80 \pm 11$ & $65 \pm 14$ & $<.001$ \\
\hline Peak flow, L/s & $4.1 \pm 1.3$ & $2.9 \pm 1.5$ & .006 \\
\hline Peak flow, $\%$ predicted & $57 \pm 18$ & $41 \pm 22$ & .008 \\
\hline Diffusing capacity of the lung for carbon monoxide, $\%$ predicted & $84 \pm 21$ & $68 \pm 23$ & .02 \\
\hline Peak maximum inspiratory pressure after cycling, $\mathrm{cm} \mathrm{H}_{2} \mathrm{O}$ & $84.9 \pm 14.7$ & $66.9 \pm 22.3$ & .02 \\
\hline \multicolumn{4}{|l|}{ 6-min walk test results } \\
\hline Breathing frequency at 6 th $\min$, breaths $/$ min & $23.5 \pm 3.6$ & $28.0 \pm 6.3$ & .004 \\
\hline Borg dyspnea score at $3 \mathrm{rd}$ min & $2.1 \pm 1.4$ & $3.4 \pm 2.5$ & .03 \\
\hline \multicolumn{4}{|l|}{$\mathrm{S}_{\mathrm{pO}_{2}}, \%$} \\
\hline At 1 st $\min$ & $94.7 \pm 1.7$ & $92.3 \pm 3.0$ & .01 \\
\hline At 3 rd min & $92.6 \pm 3.8$ & $88.6 \pm 6.7$ & .01 \\
\hline At 6 th $\min$ & $93.9 \pm 2.8$ & $89.7 \pm 5.6$ & .002 \\
\hline$\Delta \mathrm{S}_{\mathrm{pO}_{2}}$ start vs end & $1.8 \pm 3.0$ & $5.1 \pm 5.5$ & .01 \\
\hline Distance $\times$ weight, $\mathrm{kg} / \mathrm{km}$ & $28.6 \pm 4.7$ & $23.0 \pm 9.7$ & .02 \\
\hline \multicolumn{4}{|l|}{ Cycling test results } \\
\hline Peak $\dot{\mathrm{V}}_{\mathrm{O}_{2}}, \mathrm{~L} / \mathrm{min}$ & $1.3 \pm 0.3$ & $1 \pm 0.4$ & .01 \\
\hline Peak $\dot{\mathrm{V}}_{\mathrm{CO}_{2}}, \mathrm{~L} / \mathrm{min}$ & $1.3 \pm 0.3$ & $1 \pm 0.5$ & .03 \\
\hline Peak $\mathrm{O}_{2}$ pulse, $\mathrm{mL} / \mathrm{min} /$ beat & $9.6 \pm 2.5$ & $7.1 \pm 2.1$ & .01 \\
\hline$\Delta \dot{\mathrm{V}}_{\mathrm{O}_{2}} / \Delta$ work rate & $8.1 \pm 1.1$ & $6.6 \pm 2.2$ & .01 \\
\hline Peak systolic blood pressure, $\mathrm{mm} \mathrm{Hg}$ & $200.7 \pm 30.7$ & $222.3 \pm 36.7$ & .04 \\
\hline Peak minute volume, $\mathrm{L} / \mathrm{min}$ & $43.6 \pm 10$ & $36.4 \pm 13.1$ & .04 \\
\hline Peak tidal volume, $\mathrm{L}$ & $1.4 \pm 0.2$ & $1.1 \pm 0.4$ & .001 \\
\hline Peak $T_{I} / T_{\text {tot }}$ & $0.44 \pm 0.04$ & $0.41 \pm 0.05$ & .03 \\
\hline \multicolumn{4}{|l|}{$\begin{array}{l}\text { Values are mean } \pm \mathrm{SD} . \\
\dot{\mathrm{V}}_{\mathrm{O}_{2}}=\text { oxygen uptake } \\
\dot{\mathrm{V}}_{\mathrm{CO}_{2}}=\text { carbon dioxide output } \\
\text { Peak } \mathrm{O}_{2} \text { pulse }=\dot{\mathrm{V}}_{\mathrm{O}_{2}} \text { /heart rate } \\
\mathrm{T}_{\mathrm{I}}=\text { inspiratory time } \\
\mathrm{T}_{\text {tot }}=\text { total breathing cycle time }\end{array}$} \\
\hline
\end{tabular}

$\left.\mathrm{D}_{\mathrm{LCO}}\right)$, dyspnea, oxyhemoglobin saturation, and work of walking during the 6MWT, and cardiopulmonary function at peak exercise were worse in the desaturators (see Table 4). This is partly consistent with previous reports, as exertional desaturation is predicted by $\mathrm{FEV}_{1}<35 \%$ of predicted plus $\mathrm{D}_{\mathrm{LCO}}<35 \%$ of predicted, ${ }^{15}$ and is excluded by $\mathrm{D}_{\mathrm{LCO}}>55 \%$ of predicted ${ }^{15}$ or $\mathrm{FEV}_{1} / \mathrm{FVC}>0.5$ plus $\mathrm{D}_{\mathrm{LCO}}>20 \mathrm{~mL} / \mathrm{min} / \mathrm{mm} \mathrm{Hg.}{ }^{16}$ After the cycling test the inspiratory muscles are weaker in subjects with desaturation (see Table 4), indicating that oxyhemoglobin saturation may influence the recovery of inspiratory muscles after exercise. This might be concomitantly due to intercostal muscle blood flow limitation during intense exercise, as shown in near-infra-red spectroscopy. ${ }^{35}$ Exertional desaturation during a maximum exercise test may be significantly related to poorer anthropometrics and lung function at rest, and impacts the exercise capability of daily activities and submaximal and maximal exercises.

\section{MWT Versus Cycling Test}

At the start of exercise, $\mathrm{S}_{\mathrm{pO}_{2}}$ of the 6MWT was significantly lower than that of the cycling test $(P<.001$, see Table 2), which is consistent with another report. ${ }^{2}$ It is possible that there is more hyperventilation triggered by unloaded pedaling during the cycling test than that triggered by standing ready for the walk test. Unfortunately, ventilation during the walk test was not measured for comparison.

The work load in the cycling test increased more slowly than in the walk test. An incremental cycling test ideally lasts for $10 \mathrm{~min}$ so that $85 \%$ of the maximum exercise intensity takes $8.5 \mathrm{~min}$. In contrast, the intensity of walking is approximately $85 \%$ of the maximum exercise intensity for patients with COPD. ${ }^{9}$ The timing of reaching the asymptote of heart rate change during the 6MWT reportedly develops by the third minute, as in constant-work-rate 


\section{Kinetics of Changes in Oxyhemoglobin Saturation During Walking and Cycling}

Table 5. Physiologic Data and Test Results Relative to $\mathrm{S}_{\mathrm{pO}_{2}}$ Difference Between the 2 Exercise Tests

\begin{tabular}{|c|c|c|c|c|}
\hline & $\begin{array}{c}\Delta \mathrm{S}_{\mathrm{pO}_{2}} \geq 3 \% \text { in Both the } 6 \mathrm{MWT} \\
\text { and the Cycling Test } \\
(n=23,49 \%)\end{array}$ & $\begin{array}{c}\Delta \mathrm{S}_{\mathrm{pO}_{2}} \geq 3 \% \text { in Either the } 6 \mathrm{MWT} \\
\text { or the Cycling Test* } \\
(n=17,36 \%)\end{array}$ & $\begin{array}{c}\Delta \mathrm{S}_{\mathrm{pO}_{2}} \geq 3 \% \text { in Neither Test } \\
(n=7,15 \%)\end{array}$ & $P$ \\
\hline Age, y & $64.8 \pm 4.6$ & $66.7 \pm 7.2$ & $64.3 \pm 7.5$ & .55 \\
\hline Height, cm & $166.1 \pm 5.7$ & $161.4 \pm 6.2$ & $168.6 \pm 5$ & .01 \\
\hline Body mass index, $\mathrm{kg} / \mathrm{m}^{2}$ & $22.4 \pm 4.2$ & $22.2 \pm 3.3$ & $23.1 \pm 1.9$ & .45 \\
\hline Oxygen-cost diagram score, $\mathrm{mm}$ & $66 \pm 14$ & $74 \pm 14$ & $84 \pm 6$ & $<.01$ \\
\hline FVC, L & $2.7 \pm 0.7$ & $2.4 \pm 0.5$ & $2.8 \pm 0.7$ & .53 \\
\hline $\mathrm{FEV}_{1}, \mathrm{~L}$ & $1.2 \pm 0.5$ & $1.2 \pm 0.4$ & $1.4 \pm 0.3$ & .82 \\
\hline $\mathrm{FEV}_{1} / \mathrm{FVC}, \%$ & $47 \pm 15$ & $50 \pm 12$ & $50 \pm 11$ & .86 \\
\hline TLC, L & $6.3 \pm 0.9$ & $5.7 \pm 1.3$ & $6.5 \pm 1$ & .16 \\
\hline RV/TLC, \% & $54 \pm 9$ & $54 \pm 13$ & $56 \pm 10$ & .93 \\
\hline $\mathrm{D}_{\mathrm{LCO}}, \mathrm{mL} / \mathrm{mm} \mathrm{Hg} / \mathrm{min}$ & $15.6 \pm 5.6$ & $14.7 \pm 4.7$ & $19.9 \pm 6.2$ & .09 \\
\hline \multicolumn{5}{|l|}{$6 \mathrm{MWT}$ results } \\
\hline Distance, $\mathrm{m}$ & $400 \pm 111$ & $395 \pm 97$ & $474 \pm 73$ & .20 \\
\hline Distance $\times$ weight, $\mathrm{kg} / \mathrm{km}$ & $25 \pm 10$ & $24.4 \pm 5$ & $29.6 \pm 7.2$ & .37 \\
\hline Borg dyspnea score at 6 th $\min$ & $4.7 \pm 2$ & $3.6 \pm 2.2$ & $5.8 \pm 2.4$ & .08 \\
\hline \multicolumn{5}{|l|}{ Cycling test results } \\
\hline Peak $\dot{\mathrm{V}}_{\mathrm{O}_{2}}, \mathrm{~L} / \mathrm{min}$ & $0.97 \pm 0.35$ & $1.12 \pm 0.36$ & $1.38 \pm 0.36$ & .04 \\
\hline Peak $\dot{\mathrm{V}}_{\mathrm{CO}_{2}}, \mathrm{~L} / \mathrm{min}$ & $1.04 \pm 0.45$ & $1.18 \pm 0.45$ & $1.42 \pm 0.37$ & .06 \\
\hline Peak $\mathrm{O}_{2}$ pulse, $\mathrm{mL} / \mathrm{min} /$ beat & $7 \pm 1.9$ & $8.3 \pm 2.7$ & $10 \pm 2.8$ & .03 \\
\hline Peak tidal volume, $\mathrm{L}$ & $1.1 \pm 0.38$ & $1.31 \pm 0.29$ & $1.53 \pm 0.22$ & $<.01$ \\
\hline \multicolumn{5}{|c|}{$\begin{array}{l}6 \mathrm{MWT}=6 \text {-min walk test } \\
\mathrm{TLC}=\text { total lung capacity } \\
\mathrm{RV}=\text { residual volume } \\
\mathrm{D}_{\mathrm{LCO}}=\text { diffusing capacity of the lung for carbon monoxide } \\
\mathrm{V}_{\mathrm{O}_{2}}=\text { oxygen uptake } \\
\mathrm{V}_{\mathrm{CO}_{2}}=\text { carbon dioxide output } \\
\text { Peak } \mathrm{O}_{2} \text { pulse }=\mathrm{V}_{\mathrm{O}_{2}} \text { /heart rate }\end{array}$} \\
\hline
\end{tabular}

exercise. ${ }^{8}$ In turn, the exercise intensity of the early phase of $6 \mathrm{MWT}$ is much heavier than that of the cycling test, so the 6MWT causes earlier desaturation, if ever, than the cycling test (time to $\Delta \mathrm{S}_{\mathrm{pO}_{2}} \geq 3 \%$ and time to nadir $\mathrm{S}_{\mathrm{pO}_{2}}$ $1.2 \mathrm{~min}$ and $3.5 \mathrm{~min}$ vs $4.6 \mathrm{~min}$ and $6.6 \mathrm{~min}$, respectively) (see Table 2 and Figs. 1 and 3).

The resaturation that occurs in the 6MWT does not happen in the cycling test. The cycling test is an externalpacing exercise mode wherein the load is increased regularly and smoothly by a computer, whereas the walk test is an internal-pacing exercise mode controlled by subject. This notion is compatible with a previous report that resaturation occurs after rest. ${ }^{11}$

Poulain et al reported 3 subgroups of COPD desaturators: desaturation in both the 6MWT and the cycling test; desaturation in neither test; and desaturation only in the 6MWT. ${ }^{4}$ The present study had more subjects who desaturated in both tests, and fewer subjects who desaturated in neither test $(P<.001)$, and 4 unique subjects who desaturated only in the cycling test. Our subjects here may have had more severe airway obstruction than those in Poulain's study. ${ }^{4}$

Poulain et al also reported that the severity of $\mathrm{FEV}_{1}$ / FVC was related to the agreement in occurrence of de- saturation between the $6 \mathrm{MWT}$ and cycling test. ${ }^{4}$ The subgroup with desaturation in both tests had the lowest $\mathrm{FEV}_{1} /$ FVC, whereas the subgroup with desaturation in neither test had the highest. This relationship was not seen in the present study. The body height and oxygen-cost-diagram scores are significantly related across the subgroups (see Table 5). Subjects in the subgroup with desaturation in both tests had significantly less active daily lives, suggesting that the oxygen-cost-diagram score can predict exertional desaturation in both exercise modes, whereas $\mathrm{D}_{\mathrm{LCO}}$ plays only a marginal role. The discrepancies between our study and Poulain's are perhaps due to the various speeds and volitional rests in the 6MWT (see Tables 3-5).

\section{Limitations}

There are concerns regarding the accuracy of measuring saturation via pulse oximetry. ${ }^{36,37} \mathrm{We}$ validated our pulse oximeters via arterial blood gas analysis. ${ }^{12}$ The pattern of heart rate readings remained constantly exponential when there was $\mathrm{S}_{\mathrm{pO}_{2}}$ resaturation. Extraction of arterial blood during the field walk test is technically difficult in the prompt collection of arterial blood at the end of the walk test. This problem may have caused inconsistency in the 


\section{Kinetics of Changes in Oxyhemoglobin Saturation During Walking and Cycling}

previous reports. ${ }^{1,3,7}$ In a previous study, blood sampled within 15 seconds after the end of walking showed insignificant difference in $\mathrm{P}_{\mathrm{aO}_{2}}$ between the 6MWT and cycling test. ${ }^{7}$ However, 2 other reports found significant differences in $\mathrm{P}_{\mathrm{aO}} \cdot{ }^{1,3}$ Sampling blood within 15 seconds is technically demanding and inappropriate, as it was shown in this study that $\mathrm{S}_{\mathrm{pO}_{2}}$ resaturated significantly within $16 \pm 14.1$ seconds during the recovery phase of the cycling test. Although arterial blood sampling during the treadmill walk test is feasible, that test is an externalpacing modality, unlike the 6MWT. Earlobe blood sampling is a less invasive alternative, ${ }^{4}$ but it has questionable accuracy. ${ }^{38}$ Pursed-lips breathing ${ }^{39}$ could not be evaluated during the 6MWT because our study was not designed to include it. Lastly, the 6MWT performance was not significantly different across the subgroups (see Table 5) but was different between the non-desaturation and desaturation subgroups (see Table 3), suggesting a grouping effect. In Table 5 we combined into one subgroup the subjects who desaturated only in the 6MWT and the subjects who desaturated only in the cycling test, because there were only 4 subjects who desaturated only during the cycling test.

\section{Conclusions}

For the 6MWT we recommend using and reporting the start-vs-nadir $\Delta \mathrm{S}_{\mathrm{pO}_{2}}$, because the start-vs-nadir $\Delta \mathrm{S}_{\mathrm{pO}_{2}}$ is greater than the start-vs-end $\Delta \mathrm{S}_{\mathrm{pO}_{2}}$, and during the $6 \mathrm{MWT}$ the nadir $\mathrm{S}_{\mathrm{pO}_{2}}$ occurs earlier than during the cycling test. The oxygen-cost-diagram score can predict agreement in the occurrence of $\mathrm{S}_{\mathrm{pO}_{2}}$ changes in both tests. Exertional desaturation in both tests can predict poorer peak exercise performance than the 6MWT performance.

\section{REFERENCES}

1. Palange P, Forte S, Onorati P, Manfredi F, Serra P, Carlone S. Ventilatory and metabolic adaptations to walking and cycling in patients with COPD. J Appl Physiol 2000;88(5):1715-1720.

2. Hill K, Dolmage TE, Woon L, Coutts D, Goldstein R, Brooks D. Comparing peak and submaximal cardiorespiratory responses during field walking tests with incremental cycle ergometry in COPD. Respirology 2012;17(2):278-284.

3. Mahler DA, Gifford AH, Waterman LA, Ward J, Machala S, Baird JC. Mechanism of greater oxygen desaturation during walking compared with cycling in patients with COPD. Chest 2011;140(2):351358.

4. Poulain M, Durand F, Palomba B, Ceugniet F, Desplan J, Varray A, et al. 6-minute walk testing is more sensitive than maximal incremental cycle testing for detecting oxygen desaturation in patients with COPD. Chest 2003;123(5):1401-1407.

5. Spence DP, Hay JG, Carter J, Pearson MG, Calverley PM. Oxygen desaturation and breathlessness during corridor walking in chronic obstructive pulmonary disease: effect of oxitropium bromide. Tho$\operatorname{rax} 1993 ; 48(11): 1145-1150$.
6. Chilibeck PD, Paterson DH, Smith WD, Cunningham DA. Cardiorespiratory kinetics during exercise of different muscle groups and mass in old and young. J Appl Physiol 1996;81(3):1388-1394.

7. Troosters T, Vilaro J, Rabinovich R, Casas A, Barbera JA, Rodriguez-Roisin R, et al. Physiological responses to the 6-min walk test in patients with chronic obstructive pulmonary disease. Eur Respir J 2002;20(3):564-569.

8. Casas A, Vilaro J, Rabinovich R, Mayer A, Barbera JA, RodriguezRoisin R, et al. Encouraged 6-min walking test indicates maximum sustainable exercise in COPD patients. Chest 2005;128(1):55-61.

9. Chuang ML, Lin IF, Wasserman K. The body weight-walking distance product as related to lung function, anaerobic threshold and peak VO2 in COPD patients. Respir Med 2001;95(7):618-626.

10. Panos RJ, Eschenbacher W. Exertional desaturation in patients with chronic obstructive pulmonary disease. Copd 2009;6(6):478-487.

11. Fiore C, Lee A, McDonald C, Hill C, Holland A. Should oxyhaemoglobin saturation be monitored continuously during the 6-minute walk test? Chron Respir Dis 2013;8(3):181-184.

12. Chuang ML, Lin IF, Vintch JR, Ho BS, Chao SW, Ker JJ. Significant exercise-induced hypoxaemia with equivocal desaturation in patients with chronic obstructive pulmonary disease. Intern Med J 2006;36(5):294-301.

13. Minh VD, Lee HM, Dolan GF, Light RW, Bell J, Vasquez P. Hypoxemia during exercise in patients with chronic obstructive pulmonary disease. Am Rev Respir Dis 1979;120(4):787-794.

14. American Thoracic Society. Guidelines for the six-minute walk test. Am J Respir Crit Care Med 2002;166(1):111-1117.

15. Owens GR, Rogers RM, Pennock BE, Levin D. The diffusing capacity as a predictor of arterial oxygen desaturation during exercise in patients with chronic obstructive pulmonary disease. N Engl J Med 1984;310(19):1218-1221.

16. Ries AL, Farrow JT, Clausen JL. Pulmonary function tests cannot predict exercise-induced hypoxemia in chronic obstructive pulmonary disease. Chest 1988;93(3):454-459.

17. Turner SE, Eastwood PR, Cecins NM, Hillman DR, Jenkins SC. Physiologic responses to incremental and self-paced exercise in COPD: a comparison of three tests. Chest 2004;126(3):766-773.

18. GOLD C. Global strategy for the diagnosis, management, and prevention of chronic obstructive pulmonary disease (updated 2010) http://www.goldcopd.org/Guidelines/guideline-2010-goldreport.html. Accessed January 6, 2014.

19. McGavin CR, Artvinli M, Naoe H, McHardy GJ. Dyspnoea, disability, and distance walked: comparison of estimates of exercise performance in respiratory disease. BMJ 1978;2(6132):241-243.

20. Miller MR, Crapo R, Hankinson J, Brusasco V, Burgos F, Casaburi $\mathrm{R}$, et al. General considerations for lung function testing. Eur Respir J 2005;26(1):153-161.

21. Miller MR, Hankinson J, Brusasco V, Burgos F, Casaburi R, Coates AL, et al. Standardisation of spirometry. Eur Respir J 2005;26(2): 319-338.

22. Borg G. Psychophysical bases of perceived exertion. Med Sci Sports Exercise 1982;14:377-381.

23. Chuang ML, Lee CH, Lin IF. Using the oxygen-cost diagram in ramp-slope selection for dyspneic patients. Intern Med 2010;49(14): 1325-1332.

24. Jenkins S, Cecins N. Six-minute walk test: observed adverse events and oxygen desaturation in a large cohort of patients with chronic lung disease. Intern Med J 2011;41(5):416-422.

25. Cutaia M, Brehm R, Cohen M. The relationship of the BODE index to oxygen saturation during daily activities in patients with chronic obstructive pulmonary disease. Lung 2011;189(4):269-277.

26. Casanova C, Cote C, Marin JM, Pinto-Plata V, de Torres JP, Aguirre-Jaime A, et al. Distance and oxygen desaturation during the 


\section{Kinetics of Changes in Oxyhemoglobin Saturation During Walking and Cycling}

6-min walk test as predictors of long-term mortality in patients with COPD. Chest 2008;134(4):746-752.

27. Garcia-Talavera I, Garcia CH, Macario CC, de Torres JP, Celli BR, Aguirre-Jaime A. Time to desaturation in the 6-min walking distance test predicts 24-hour oximetry in COPD patients with a $\mathrm{P}_{\mathrm{O}_{2}}$ between 60 and 70mmHg. Respir Med 2008;102(7):1026-1032.

28. Luxton N, Alison JA, Wu J, Mackey MG. Relationship between field walking tests and incremental cycle ergometry in COPD. Respirology 2008;13(6):856-862.

29. Mak VH, Bugler JR, Roberts CM, Spiro SG. Effect of arterial oxygen desaturation on six minute walk distance, perceived effort, and perceived breathlessness in patients with airflow limitation. Thorax 1993;48(1):33-38

30. Gunen H, Kosar F. Spirometric predictors for the exclusion of severe hypoxemia in chronic obstructive pulmonary disease. Can Respir J 2001;8(4):245-249.

31. Hadeli KO, Siegel EM, Sherrill DL, Beck KC, Enright PL. Predictors of oxygen desaturation during submaximal exercise in 8,000 patients. Chest 2001;120(1):88-92.

32. D'Urzo AD, Mateika J, Bradley DT, Li D, Contreras MA, Goldstein RS. Correlates of arterial oxygenation during exercise in severe chronic obstructive pulmonary disease. Chest 1989;95(1):13-17.
33. Gallagher CG. Exercise limitation and clinical exercise testing in chronic obstructive pulmonary disease. Clin Chest Med 1994;15(2):305-326.

34. Christensen CC, Ryg MS, Edvardsen A, Skjonsberg OH. Relationship between exercise desaturation and pulmonary haemodynamics in COPD patients. Eur Respir J 2004;24(4):580-586.

35. Vogiatzis I, Athanasopoulos D, Habazettl H, Aliverti A, Louvaris Z, Cherouveim E, et al. Intercostal muscle blood flow limitation during exercise in chronic obstructive pulmonary disease. Am J Respir Crit Care Med 2010;182(9):1105-1113.

36. Barthelemy JC, Geyssant A, Riffat J, Antoniadis A, Berruyer J, Lacour JR. Accuracy of pulse oximetry during moderate exercise: a comparative study. Scand J Clin Lab Invest 1990;50(5):533-539.

37. Yamaya Y, Bogaard HJ, Wagner PD, Niizeki K, Hopkins SR. Validity of pulse oximetry during maximal exercise in normoxia, hypoxia, and hyperoxia. J Appl Physiol 2002;92(1):162-168.

38. Eaton T, Rudkin S, Garrett JE. The clinical utility of arterialized earlobe capillary blood in the assessment of patients for long-term oxygen therapy. Respir Med 2001;95(8):655-660.

39. Faager G, Stahle A, Larsen FF. Influence of spontaneous pursed lips breathing on walking endurance and oxygen saturation in patients with moderate to severe chronic obstructive pulmonary disease. Clin Rehabil 2008;22(8):675-683.

This article is approved for Continuing Respiratory Care Education credit. For information and to obtain your CRCE

(free to AARC members) visit

www.rcjournal.com 